uraemia in their patients. Infusion of albumin and mannitol, alone or in combination, could have contributed to the reversal of any of these postulated mechanisms of uraemia.

Whatever the mechanism of improvement we have observed, the clinical implication is clear: the absence of hypotension should not deter an attempt to initiate diuresis by albumin or mannitol infusion, or both, in nephrotic patients with uraemia and oedema resistant to conventional diuretic therapy. Scrupulous observation of such patients to minimise the risk of volume overload and of pulmonary oedema is mandatory.

The salt-poor human albumin used in the infusions was prepared by the Blood Products Laboratory, Lister Institute, Elstree, Herts. Maximum sodium content $65 \mathrm{mmol} / 100 \mathrm{~g}$ albumin. Each $25 \mathrm{~g}$ of freeze-dried albumin was dissolved in $150-250 \mathrm{ml}$ sterile water before infusion. Renal biopsies were examined by light and electron microscopy in all cases and by immunofluorescence in case 3 .

We thank Professor J E Lennard-Jones, Dr R J Davies, and Dr A Freedman, who referred cases 1,2 , and 3 respectively.

1 Chamberlain, M J, et al, Quarterly fournal of Medicine, 1966, 35, 215.

${ }^{2}$ Lowenstein, J, et al, Kidney International, 1978, 14, 656.

(Accepted 8 fuly 1979)

St Bartholomew's Hospital Medical College and St Bartholomew's Hospital, London EC1A 7BE

V J STEPHENS, medical studen:

A P B YATES, medical student

R I LECHLER, MB, MRCP, senior house officer

L R I BAKER, MD, FRCP, consultant physician

\section{Running and stress fractures}

Running is becoming increasingly popular. We have encountered increasing numbers of stress fractures of the legs in runners. Runners often continue to run despite pain and even stress fractures. Most such fractures heal uneventfully with rest, but we have seen one woman who continued to run while experiencing pain and then sustained a complete fracture of the tibia. We now report on a runner who believed that her leg pains would disappear if she strengthened her legs by more running.

\section{Case report}

A 28-year-old woman presented with pain in the anterior aspects of both legs of two weeks' duration. The pain was present only while running. She had noted tender bumps on both shins and concluded that her pain was not due to "normal" shin splints, meaning anterior tibial-muscle soreness, from which many runners suffer during early training. She had been running almost daily for three years, and during the previous 10 months had averaged 45 miles a week. She had practised judo two or three times a week during the previous 15 months. Apart from her leg pains she was in excellent health. Her history was unremarkable.

The only abnormalities on physical examination were tender irregularities on the crests of both tibiae. All routine laboratory tests including alkaline phosphatase activity and Wassermann reaction were normal. She manifested intense anxiety about having to discontinue running. The figure shows $x$-ray films of both tibiae and fibulae. A skeletal survey showed no abnormalities apart from extensive periosteal new bone formation in both femora.

She was given crutches for one month, during which time she became aware of pain at rest. When told that she had sustained stress fractures she stated that the pain had been present for two months but she had continued to run because it made her feel so relaxed. During the four-month recovery period when $x$-ray films showed complete healing of the fractures she was agitated and irritable and repeatedly consulted us to express her anxiety. When she restarted running her anxiety and agitation subsided.

\section{Comment}

This case is the most extreme case of shin splints that we have encountered or have found described. ${ }^{1}$ This radiological syndrome was first described by Devas $^{2}$ and is different from the clinical syndrome of the same name due to ischaemia of the anterior tibial muscles. The $x$-ray appearance of shin splints may mimic any process

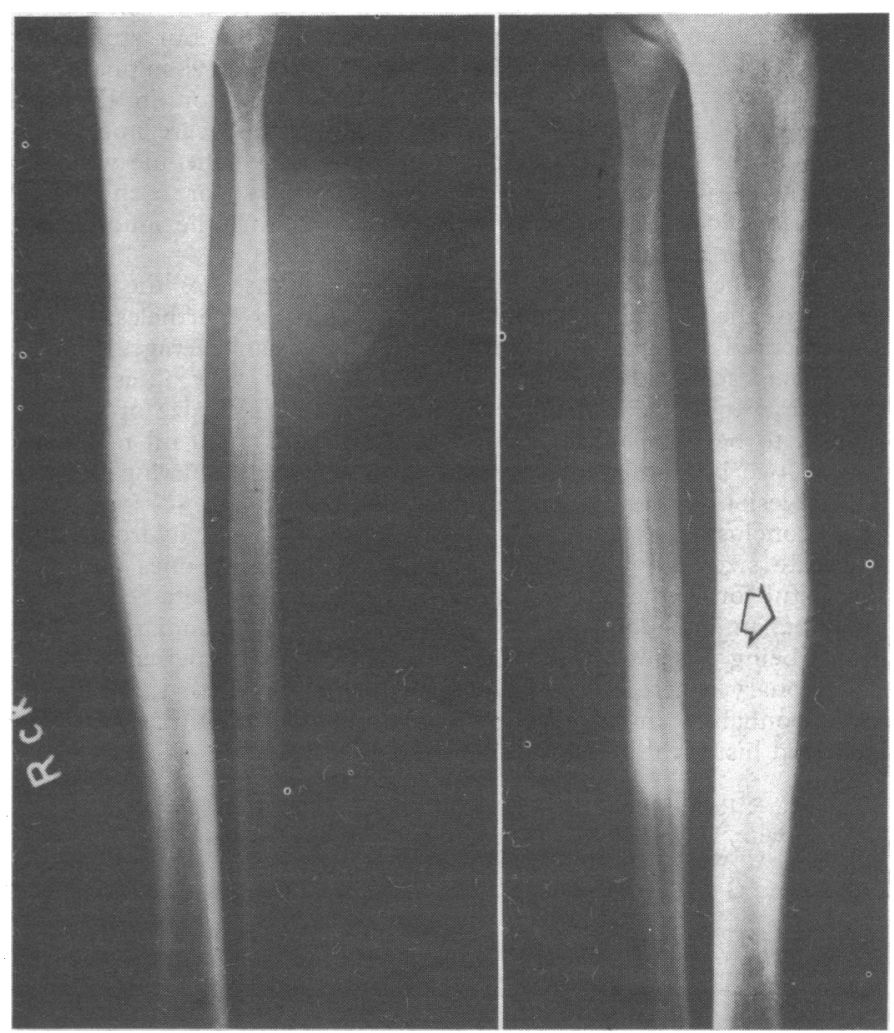

Lateral views of leg showing barely visible multiple miniscule lucent lines, one of which is easily identified on anterior aspect of tibial cortex (arrowed). They represent osteoid seaming of multiple stress fractures. Appreciable cortical and hyperostotic thickening of the tibia and fibula is apparent with encroachment on the medullary canal.

with new bone formation-for example, adult lues (sabre shin), healed rickets, osteogenic sarcoma, and foreign-body "tumour." In most cases the clinical picture will clarify the diagnosis. A stress fracture usually shows no abnormality on an $x$-ray film until two to four weeks after the onset of symptoms, when the only evidence may be subperiosteal new bone formation over the fracture; a translucency representing the fracture site may perhaps be seen. In addition to stress fractures and new bone formation in the tibiae in this patient there was new bone formation in the fibulae and femora. These changes probably resulted from underlying stress fractures or the pull of tendinous attachments (cortical hyperostosis and traction periostosis). The symmetry of these changes suggests that they were chiefly caused by running, although judo may have contributed.

Glasser ${ }^{3}$ described running as a "positive addiction" for regular adherents, who, when they are unable to run, experience a withdrawal syndrome. Greist et $a l^{4}$ found running to be as effective in treating mild to moderate depression as psychotherapy; they reviewed the reports of other workers who have successfully used running to treat phobias, anxiety neurosis, schizophrenia, and anorexia nervosa. Thus if a runner is (unknowingly) successfully treating himself for any of the above disorders he would probably minimise any symptoms that might prevent him from running. Noakes $e^{t} a^{5}$ reported on six cases of myocardial infarction in runners, of which one was fatal; all these runners had warning symptoms, which they ignored.

1 Yale, J, Fournal of the American Podiatry Association, 1976, 66, 639.

2 Devas, M B, fournal of Bone and foint Surgery, 1958, 40B, 227.

3 Glasser, W, Positive Addiction. Hagerstown, Maryland, Harper and Row, 1976.

4 Greist, J H, et al, Comprehensive Psychiatry. In press.

5 Noakes, T, et al, Annals of the New York Academy of Sciences, 1977, 301; 593.

(Accepted 22 fune 1979)

St Luke's Hospital Centre, New York 10025

E W D COLT, MRCP, FACP, assistant attending physician, department of medicine

E SPYROPOULOS, MD, attending physician, department of radiology 